\title{
Self-care practices among diabetes patients registered in a chronic disease clinic in Puducherry, South India
}

\author{
Kalaiselvi Selvaraj, Gomathi Ramaswamy, Shrivarthan Radhakrishnan, Pruthu Thekkur, Palanivel Chinnakali, \\ Gautam Roy \\ Department of Preventive and Social Medicine, Jawaharlal Institute of Postgraduate Medical Education and Research (JIPMER), Puducherry, India
}

\section{A B S T R A C T}

Background: In management of diabetes, self-care plays an important role in prevention of complications. This study aims to find the proportion of diabetic patients following the recommended self-care practices in an urban area of Puducherry. Materials and Methods: Consecutive eligible patients registered in chronic disease clinic were interviewed using Summary of Diabetes Self Care Activities Score (SDSCA) questionnaire. Self-care practices were evaluated in domains of diet, physical activity, foot-care, adherence to medications and blood glucose monitoring. All domains were scored from the range of 0 to 7. Results: Totally 162 diabetic patients were interviewed. The mean (SD) age of participants was 57 (II.I) yrs. Among all domains, adherence to medication was the highest (95.6\%) followed by avoidance of selected food items (99.4\%). Almost $78 \%$ of patients had their blood sugar checked at least once in the last three months. Only half of them (50.6\%) had followed at least 20 minutes of leisure time physical activity. Except washing of foot (83.3\%) all other foot care practices were less commonly (35-57\%) followed. Conclusion: The study shows that higher level of compliance to self-care practices in terms of taking drugs and diet but self-care in other domains such as foot care is alarmingly low.

Key words: Compliance, diabetes, diabetes self care, diabetic foot care, summary of diabetes self-care activities (SDSCA) score

\section{INTRODUCTION}

India is the second most populous country to have a large number of people affected with diabetes. In India, 65.1 million people are affected by diabetes and that number will increase to 109 million by 2035 . Recent estimates suggested that the prevalence of diabetes among adults (aged 20-79 years) was about $8.6 \% \cdot{ }^{[1]}$ Besides morbidities and increased health care expenditures, diabetes is related to many catastrophic life-threatening complications such as coronary heart disease, stroke, diabetic foot, and chronic

\begin{tabular}{|l|l|}
\hline \multicolumn{2}{|c|}{ Access this article online } \\
\hline Quick Response Code: & Website: \\
\hline & www.joshd.net \\
\hline & \\
\hline & \\
\hline
\end{tabular}

renal failure. Often, people become aware of their diabetic status for the first time after developing complications related to diabetes. ${ }^{[2]}$ Factors such as gender (being a female), illiteracy, lack of health literacy, poor access to health care, and lack of family support mechanisms were found to be associated with poor compliance in diabetes management. ${ }^{[3-5]}$ Yet these findings could be different in different settings due to differences in lifestyle pattern and in access to the health care system. More than $80 \%$ of diabetics live in middle- and low-income countries This is an open access article distributed under the terms of the
Creative Commons Attribution-NonCommercial-ShareAlike 3.0
License, which allows others to remix, tweak, and build upon the
work non-commercially, as long as the author is credited and the
new creations are licensed under the identical terms.

For reprints contact: reprints@medknow.com

How to cite this article: Selvaraj K, Ramaswamy G, Radhakrishnan S, Thekkur P, Chinnakali P, Roy G. Self-care practices among diabetes patients registered in a chronic disease clinic in Puducherry, South India. J Soc Health Diabetes 2016;4:25-9.

Corresponding Author: Dr. Kalaiselvi S, Department of Preventive and Social Medicine, Jawaharlal Institute of Post Graduate Medical Education and Research (JIPMER), Puducherry - 605 006. India. E-mail: kalaiselvi.dr@gmail.com 
(LMICs), where health systems are already burdened with infectious diseases and child and maternal health problems. Diabetes, a chronic disease, needs lifelong commitment. Hence, it is essential to promote self-care practices among diabetics, especially in LMICs, as these practices help in avoiding or delaying the complications of diabetes.

There are seven principles proven to be effective with diabetes management: Healthy eating, being active, monitoring, taking medication, problem solving, healthy coping, and reducing risks. ${ }^{[6]}$ Of these seven principles, dietary intake, physical activity, adherence to medications, and periodic health checkups are usually assessed in primary care settings to know about selfcare practices. Self-care practices are defined as the set of behaviors practiced by people with or at risk of diabetes in order to successfully manage the disease on their own. ${ }^{[7]}$ These self-care practices are found to have an association with good glycemic control and thereby controlled incidence of macro- and microvascular complications, too. ${ }^{[8]}$ Though various scales are available to assess self-care practices, a revised summary of diabetes self-care activities (SDSCA) score was reported to be most valid and reliable. ${ }^{[9]}$ Despite the fact that $80 \%$ of diabetics live in LMICs, there is a dearth of literature on self-care practices from these countries. This study aims to find the proportion of diabetic patients following the recommended self-care practices related to diabetes in terms of dietary modification, behavior of exercise, foot care, blood sugar checkup at periodic intervals, and adherence to medications.

\section{MATERIALS ANd MethodS}

A facility-based cross-sectional study was conducted at an urban health center, Puducherry, India during December 2013. This urban health center caters to a population of 9,600 from four urban areas of Puducherry. Any individual who was diagnosed to have diabetes or hypertension (either at the urban health center or from other hospitals) was registered in a chronic disease clinic of urban health center. Around 230 diabetic individuals are registered in the chronic disease clinic in the study setting. The clinic is conducted once weekly and managed by the Medical Officer of the urban health center. All diabetics registered in the chronic disease clinic from the study setting constituted the study population.

After obtaining verbal consent, consecutive diabetic patients were interviewed regarding diabetes self-care practices and related sociodemographic variables.
A structured questionnaire on SDSCA was modified to this study context and it was translated into the Tamil language, pretested, and used. This questionnaire checks the frequency with which diabetics have followed the prescribed self-care practices in the last 7 days. In total, five domains were studied using SDSCA. The dietary domain covered a total of five items, namely, frequency of avoiding sweets, frequency of consuming fat-rich foods, having snacks during the mid-lunch and evening periods, restricting the quantity of cereals consumed, and consumption of fruits and vegetables. Similarly, foot care covered five items: Soaking of feet, inspecting sandals/shoes every day, washing of feet, drying of feet in between the toes and inspection of feet every day. The exercise domain covered two items of workrelated and leisure-time physical activity. Adherence to medication measures covered two items (following prescribed schedule of insulin regimen, consumption of prescribed oral hypoglycemic agents). Self-care practices under each item were scored between 0 (none of the days in a week) to 7 (all 7 days were followed). Each participant's glycemic status in the last 3 months was also reviewed.

\section{Scoring of individual domains}

All items were positively scored except consumption of fat-rich items in the dietary domain and soaking of feet in the foot care domain. Hence, reverse scoring was done for the two items mentioned above. In the dietary domain, appropriate self-care was ascertained if the patient had followed the self-care measures more than $75 \%$ of the time in a week. For this purpose, a cumulative score was calculated from all five items and was converted to percentage. Similarly, for foot care the same definitions were followed. The exercise domain was defined as satisfactory if the patient had followed at least 5 days of leisure-time and work-related physical activity for at least $20 \mathrm{~min}$ in 1 week. Adherence was measured as following prescribed medications on at least 6 days of the week. If any diabetic patient had not checked their blood sugar at least once in the past 3 months, adherence was considered unsatisfactory.

Data were entered in EpiData version 3.1 (The EpiData Association, Odense, Denmark) and analysis was done in Stata 11.0 (StataCorp, College Station, Texas, USA). Descriptive statistics such as mean [standard deviation (SD)] and percentages were used for continuous and categorical variables, respectively. Proportions of patients following selected self-care domains were presented as percentages. 


\section{RESULTS}

A total of 162 diabetics were interviewed; of them $133(82.1 \%)$ were females. The mean (SD) age of diabetics was 57 (11.1) years. Most of them (66\%) belonged to the lower middle class as per the modified Kuppuswamy scale (2012). The sociodemographic profile of diabetics is presented in Table 1.

Among diabetics, the proportion consuming tobacco and alcohol were found to be $18.5 \%$ and $3.7 \%$, respectively. In total, $25.3 \%$ of diabetics had reported a family history of diabetes mellitus. The majority of them $(98.1 \%)$ are on oral hypoglycemic drugs; $63.6 \%$ of study participants had at least one chronic disease conditions; and more than half of the diabetics (57.4\%) were found to have coexisting hypertension. A majority of the diabetics $(54.9 \%)$ were diagnosed first incidentally during a visit to the urban health center or during the camp. More than $94 \%$ of them were diagnosed at least 1 year before the study period.

\begin{tabular}{|c|c|}
\hline Sociodemographic factors & $N(\%)$ \\
\hline \multicolumn{2}{|l|}{ Age groups (in years) } \\
\hline $28-50$ & $52(32.1)$ \\
\hline $51-60$ & $51(31.5)$ \\
\hline$>60$ & $59(36.4)$ \\
\hline \multicolumn{2}{|l|}{ Gender } \\
\hline Male & $29(17.9)$ \\
\hline Female & $133(82.1)$ \\
\hline \multicolumn{2}{|l|}{ Education } \\
\hline No formal education & $60(37.0)$ \\
\hline $1^{\text {st }}-5^{\text {th }}$ std. & $40(24.7)$ \\
\hline $6^{\text {th }}-8^{\text {th }}$ std. & $33(20.4)$ \\
\hline More than middle school & $29(17.9)$ \\
\hline \multicolumn{2}{|l|}{ Occupation } \\
\hline Unemployed & $23(14.2)$ \\
\hline Unskilled & $96(59.3)$ \\
\hline Semiskilled & $19(11.7)$ \\
\hline Skilled/professional & $15(9.3)$ \\
\hline Agricultural workers, self employed & $9(5.6)$ \\
\hline \multicolumn{2}{|l|}{ Per capita income (INR) } \\
\hline$<1589$ & $107(66)$ \\
\hline $1589-4726$ & $45(27.8)$ \\
\hline $4727-7877$ & $6(3.7)$ \\
\hline $7878-11816$ & $1(0.6)$ \\
\hline $11817-15753$ & $2(1.2)$ \\
\hline$>15753$ & $1(0.6)$ \\
\hline \multicolumn{2}{|l|}{ Socioeconomic status* } \\
\hline Lower & $44(27.2)$ \\
\hline Upper lower & $9(5.6)$ \\
\hline Lower middle & $107(66)$ \\
\hline Upper middle & $2(1.2)$ \\
\hline \multicolumn{2}{|l|}{ Living arrangement } \\
\hline Living alone & $18(11.1)$ \\
\hline Living with spouse & $97(59.9)$ \\
\hline Living with family & $47(29.0)$ \\
\hline
\end{tabular}

*Socioeconomic status as per modified Kuppuswamy scale (2012)
Among all domains, adherence to medication was the highest $(95.6 \%)$. Of all the patients, $78.8 \%$ had their blood sugar checked at least once in the last 3 months. Though patients were cautious about avoiding selected food items (99.4\%), only two-third of patients had complied with consumption of regular intake of vegetables and decreasing the serving size of each meal (63-67\%). Only half of them (50.6\%) had followed at least $20 \mathrm{~min}$ of leisure-time physical activity. Except washing of feet (83.3\%), all other foot care practices were less commonly (35-57\%) followed [Table 2]. Based on the domain score, only one-third of patients followed satisfactorily in the diet and exercise domains. The domain score on foot care was especially lowest of all domains [Table 3].

\section{DISCUSSION}

This facility-based study on self-care practices among diabetics showed a high level of adherence to medications (95.6\%) as well as work-related physical activity (82.1\%). Levels of self-care practices followed in this study setting are high compared to other study reports. ${ }^{[5,10]} \mathrm{A}$ study from the Vellore region of Tamil Nadu using the same study tool had reported higher adherence to medication (79.8\%) comparable to the present study. ${ }^{[7]}$ The study also reported good dietary behavior, physical activity, and regular blood sugar monitoring among $30 \%, 20 \%$, and $70 \%$ of diabetics, respectively. ${ }^{[7]}$ Self-care practices in the domains of foot care and diet were not followed by $70 \%$ and $90 \%$ of diabetics, respectively, in a study done in Bangladesh. ${ }^{[5]}$ A study from a tertiary care institute of Andhra Pradesh had shown that $56 \%$ of diabetic patients do not comply with their meal plan. This study had also shown $61 \%$ and $63 \%$ of satisfactory behavior against physical activity and adherence to medication, respectively. Practices of foot care were less prevalent, as reported in these studies $(35 \%){ }^{[10]}$ The differences in self-care practices could be due to easier access to health-related activities and higher proportions of literate population in the present study setting. A chronic disease clinic, which is being conducted on every Wednesday at the study center, facilitates regular blood sugar monitoring and uninterrupted supply of medications. Besides these factors, as this study was facility-based, those who come to the center are persons who have better health care behavior compared to persons from community who have not made any visits. Findings could also differ based on which phase of their illness (the period from diagnosis of diabetes to the study period) participants were recruited. Some studies were conducted exclusively among newly diagnosed diabetics. ${ }^{[5]}$ In this study, around $94 \%$ of them were diagnosed at least 1 year before. Newly diagnosed diabetic individuals and chronic 


\begin{tabular}{|c|c|c|}
\hline \multirow[t]{2}{*}{ Diabetes self-score items } & \multicolumn{2}{|c|}{$(N=162)$} \\
\hline & Satisfactory & Not satisfactory \\
\hline \multicolumn{3}{|l|}{ Diet* $^{*}$} \\
\hline Following the advice given by treating physician in selection of food items & $161(99.4)$ & $1(0.6)$ \\
\hline Consuming high-fat foods such as red meat, dairy products in a week & $1(0.6)$ & $161(99.4)$ \\
\hline Frequency of meals (at least five times spaced out) & $60(37)$ & $102(62.3)$ \\
\hline Eating fruits and vegetables at least 5 days in a week & $102(63)$ & $60(37)$ \\
\hline Reduced the serving size of cereal-based food items & $108(66.7)$ & $54(33.3)$ \\
\hline \multicolumn{3}{|l|}{ Physical activity* } \\
\hline $\begin{array}{l}\text { More than } 30 \text { min of physical activity at least } 5 \text { days in a week, including } \\
\text { work-related }\end{array}$ & $123(82.1)$ & 39 (17.9) \\
\hline More than 20 min of leisure-time physical activity at least 5 days in a week & $82(50.6)$ & $80(49.4)$ \\
\hline \multicolumn{3}{|l|}{ Foot care* } \\
\hline Examining feet to look for corns, fissures, etc. & $93(57.4)$ & $69(42.6)$ \\
\hline Soaking of feet & $70(43.2)$ & $92(56.8)$ \\
\hline Examination of sandals to look for any sharps & $57(35.2)$ & $105(64.8)$ \\
\hline Drying of feet in between toes & $66(40.7)$ & $96(59.3)$ \\
\hline Washing of feet & $135(83.3)$ & $27(16.7)$ \\
\hline \multicolumn{3}{|l|}{ Adherence to drugs* } \\
\hline $\begin{array}{l}\text { Taking antidiabetic drugs as prescribed for at least } 6 \text { days in a week } \\
\text { Blood sugar checkup }\end{array}$ & $152(95.6)$ & $7(4.4)$ \\
\hline Checked blood sugar at least once in last 3 months & $119(78.8)$ & $32(21.2)$ \\
\hline
\end{tabular}

${ }^{*}$ Denotes domains under SDSCA questionnaire

\begin{tabular}{|c|c|c|}
\hline Self-care practices domain & Adequate & Unsatisfactory \\
\hline Diet & $37(32.8)$ & $125(77.2)$ \\
\hline Exercise & $54(33.3)$ & $108(66.7)$ \\
\hline Foot care & $14(8.6)$ & $148(91.4)$ \\
\hline Adherence to medications* & $152(95.6)$ & $7(4.4)$ \\
\hline Appropriate blood sugar checkup ${ }^{\dagger}$ & 119 (78.8) & $32(21.2)$ \\
\hline
\end{tabular}

${ }^{\star} 3$ on insulin, ${ }^{\dagger} 11$ values missing

diabetic individuals suffering from certain macro- or microvascular complications are more likely to comply with these self-care practices compared to chronic diabetics without any complications. Regardless of the settings where the study being conducted, self-care practices in compliance with medications were high and this was least related to foot care. ${ }^{[5,7,10,11]}$

As this is a facility-based study, interpretations should be made with caution. The level of self-care practices among the total 230 diabetic patients registered in chronic disease clinic, 162 were able to contact during study period. Hence, the non response rate was 30\%. The majority of individuals who did not participate in this study were males. The reason for nonresponse among men was mainly fear of loss of wages on the day of the visit. Moreover, the social desirability bias against dietary practices and, especially, foot care cannot be ruled out. This study did not report the effect of self-care practices on glycemic control.
Though this study shows a high level of adherence to diabetic medication, other domains such as leisure timerelated physical activity, dietary practices, and, especially, foot care practices need to be strengthened. Unless there is a provision of integrated care under one roof with personnel trained in nutrition and podiatric divisions, improvement in self-care practices in these domains is unlikely to be achieved.

\section{Acknowledgement}

We would like to acknowledge the MBBS trainees, Medical Officer Dr. Jagdeeswaran, the staff, and the Medical Social Worker for their kind cooperation in conducting the study.

Financial support and sponsorship

Nil.

\section{Conflicts of interest}

There are no conflicts of interest

\section{REFERENCES}

1. World Diabetes Atlas (2013). International Diabetes Federation (IDF). $6^{\text {th }}$ ed. Available from: http://www.idf.org/sites/default/files/ EN_6E_Atlas_Full_0.pdf. [Last accessed on 2014 Jun 15].

2. Sosale A, Prasanna Kumar KM, Sadikot SM, Nigam A, Bajaj S, Zargar $\mathrm{AH}$, et al. Chronic complications in newly diagnosed patients with Type 2 diabetes mellitus in India. Indian J Endocrinol Metab 2014;18:355-60.

3. Vanstone M, Giacomini M, Smith A, Brundisini F, DeJean D, Winsor S. How diet modification challenges are magnified in vulnerable or marginalized people with diabetes and heart disease: A systematic review and qualitative meta-synthesis. Ont Health Technol Assess Ser 2013;13:1-40. 
4. Al-Maskari F, El-Sadig M, Al-Kaabi JM, Afandi B, Nagelkerke N, Yeatts KB. Knowledge, attitude and practices of diabetic patients in the United Arab Emirates. PloS One 2013;8:e52857.

5. Saleh F, Mumu SJ, Ara F, Begum HA, Ali L. Knowledge and self-care practices regarding diabetes among newly diagnosed type 2 diabetics in Bangladesh: A cross-sectional study. BMC Public Health 2012;12:1112.

6. Shrivastava SR, Shrivastava PS, Ramasamy J. Role of self-care in management of diabetes mellitus. J Diabetes Metab Disord 2013;12:14.

7. Gopichandran V, Lyndon S, Angel MK, Manayalil BP, Blessy KR, Alex RG, et al. Diabetes self-care activities: A community-based survey in urban southern India. Natl Med J India 2012;25:14-7.
8. Marques MB, da Silva MJ, Coutinho JF, Lopes MV. Assessment of self-care competence of elderly people with diabetes. Rev Esc Enferm USP 2013;47:415-20.

9. Toobert DJ, Hampson SE, Glasgow, RE. The summary of diabetes self-care activities measure: Results from 7 studies and a revised scale. Diabetes Care 2000;23:943-50.

10. Sasi ST, Kodali M, Burra KC, Muppala BS, Gutta P, Bethanbhatla MK Self care activities, diabetic distress and other factors which affected the glycaemic control in a tertiary care teaching hospital in south India. J Clin Diagn Res 2013;7:857-60.

11. Schiøtz M, Strandberg-Larsen M, Frølich A, Krasnik A, Bellows J, Kristensen JK, et al. Self-management support to people with type 2 diabetes-a comparative study of Kaiser Permanente and the Danish Healthcare System. BMC Health Serv Res 2012;12:160. 